\section{Palabras del director}

\author{
Words From the Director
}

Hoy el Departamento de Diseño ha puesto en circulación, con gran esfuerzo de un grupo de académicos, la revista RChD: creación y pensamiento. Aunque no es primera vez que ello ocurre (hubo otros números impresos anteriormente, pero no tuvieron continuidad), estamos embarcados en un proyecto de envergadura donde la diferencia respecto de la experiencia anterior radica, tal vez, en las complejidades que han debido enfrentar ambas iniciativas: la primera, coincidente con el inicio y fundación del DdD en la Facultad de Arquitectura y Urbanismo de la Universidad de Chile; la actual, con la conformación de un equipo participativo, heterogéneo, pero muy comprometido, inmerso en el ámbito de las publicaciones digitales.

Sin duda, este proyecto ha podido además desarrollarse gracias al apoyo del Decanato de la Facultad de Arquitectura y Urbanismo y de su Dirección de Investigación y Desarrollo, así como de la Vicerrectoría de Investigación y Desarrollo (VID) de la Universidad de Chile, en el marco del proyecto de fortalecimiento de todas las publicaciones científicas FAU.

Iniciamos un nuevo rumbo para esta publicación. Aspiramos, en un breve plazo, a indexarla y que se convierta en un espacio para promover el conocimiento en torno al Diseño y aportarlo, con reciprocidad, a la sociedad que le da su sentido. Nos cabe la convicción de que con esta labor, esto es la publicación de la revista, estamos construyendo y articulando lo disciplinar del Diseño. Hoy, ya más consolidados, nos sentimos capaces de conquistar otros desafíos. En esta oportunidad la revista circulará prioritariamente en formato digital y estará albergada en ojs (Open Journal Systems, plataforma de administración de todas las revistas de la Universidad de Chile), con lo cual se potenciará su visibilidad y acceso gratuito a una comunidad mucho más amplia, diversa y dispersa geográficamente, que podrá acceder a todos sus contenidos a través de internet.

Desde el punto de vista de sus abordajes, nuestra idea es que no solo acoja los temas de Diseño, sino también todos los otros tópicos que circulan en torno a él, facilitando un desplazamiento desde lo disciplinar hacia otros campos y aportando al mundo científico, la creación y el pensamiento. Inauguramos este nuevo espacio, necesario para el Diseño nacional, que esperamos se vaya consolidando como un lugar de encuentro para la lectura y escritura de los diseñadores, de otros profesionales e investigadores interesados tanto de la disciplina como en áreas afines. Con ello, además de orientarnos hacia nuestro campo de desarrollo, abrirnos a la interdisciplinariedad, al vínculo con la sociedad y el territorio. Queremos ser un relato vivo que recoja la mirada crítica de la producción disciplinar y representar una contribución al objetivo superior que soñaron los fundadores del Diseño mundial: mejorar la calidad de vida de las personas. Es la idea que nos guía y queremos inculcar tanto en quienes escribirán en estas páginas, como en aquellos que las leerán desde hoy.

No queda más que invitar a aquellos que deseen publicar en el futuro próximo sus investigaciones de carácter científico y darles la más cordial bienvenida. 